Research Article

\title{
Awareness regarding Zika Virus Disease among Resident Doctors of a Tertiary Hospital in Goa
}

Jagadish A Cacodcar', Abhishek U Bicholkar', Prathamesh S Sawant ${ }^{2}$, Prasida P Dessai ${ }^{4}$, Shivohn A Da Silva ${ }^{5}$, Moushmi S Pednekar $^{6}$, Rhea Y De Souza ${ }^{7}$, Snehankita S Shet ${ }^{8}$, Rochelle M Fernandes ${ }^{9}$, Shrijha A Kerkar'", Shalaka S Mayekar", Shriganesh Y Nagvenkar', Prajakta A Patil ${ }^{13}$, Leanne S Fernandes ${ }^{14}$, Carissa S D'silva ${ }^{15}$, Nidhi B Gawas $^{16}$, Viola Quadros $^{17}$

${ }^{1}$ Professor and Head of Department, Department of Preventive and Social Medicine, Goa Medical College, Goa, India.

${ }^{2}$ Post Graduate Student, Department of Preventive and Social Medicine, Goa Medical College, Goa, India.

$3,4,5,6,7,8,9,10,11,12,13,14,15,16,17$ MBBS Student, Goa Medical College, Goa, India.

DOI: https://doi.org/10.24321/2454.325X.202003

\section{I $\quad \mathbf{N} \quad \mathbf{F} \mathbf{O}$}

\section{Corresponding Author:}

Abhishek U Bicholkar, Department of Preventive and Social Medicine, Goa Medical College, Goa, India.

E-mail Id:

abicholkar@yahoo.com

Orcid Id:

https://orcid.org/0000-0002-2418-1665

How to cite this article:

Cacodcar JA, Bicholkar AU, Sawant PS, Dessai PP, Da Silva SA, Pednekar MS et al. Awareness regarding Zika Virus Disease among Resident Doctors of a Tertiary Hospital in Goa. Int J Preven Curat Comm Med 2020; 6(1): 20-24.

Date of Submission: 2020-05-26

Date of Acceptance: 2020-09-16

\section{$\begin{array}{llllllll}\text { A } & \text { B } & \mathbf{S} & \mathbf{T} & \mathbf{R} & \mathbf{A} & \mathbf{C} & \mathbf{T}\end{array}$}

Background: Among the emerging diseases, Zika virus (ZIKV) disease, a vector-borne health problem, has recently become a major VBD of international concern in low and middle income countries. In India, the first four proven cases of ZIKV were reported in 2017 followed by major outbreaks in the States of Rajasthan and Madhya Pradesh. This study was conducted to assess the knowledge and awareness of Resident doctors in Goa towards managing ZVD in a tertiary care hospital in Goa.

Methods: The present hospital-based cross-sectional study was conducted among Resident doctors of Goa Medical College and Hospital. A total of 188 Resident doctors from various Departments were interviewed to obtain details regarding personal characteristics and their knowledge regarding the Zika virus disease.

Result: A high number i.e. 139 (73.9\%) of the Resident doctors were aware of the mosquito vector that transmits Zika disease. Only 23 (12.4\%) of the Resident doctors were aware of the common symptoms and signs seen in cases of Zika virus disease. A majority of the Resident doctors i.e. 154 (81.9\%) were aware of the most common adverse outcome of maternal Zika virus infection. A high number i.e. 183 (97.3\%) Resident doctors correctly said that Zika virus disease can be prevented and 180 (95.7\%) of the Resident doctors were aware of the preventive measures for Zika virus infection.

Conclusion: The knowledge of Resident doctors in Goa regarding the Zika virus disease is low especially regarding the modes of transmission, signs and symptoms and diagnosis of the Zika infection. It is necessary that basic knowledge and training regarding the Zika virus disease should be included in the current medical curriculum. Regular CME programs on ZVD for the training of the Resident doctors and trainee medical doctors must be conducted.

Keywords: Zika Virus Disease, Mosquito Vector, Awareness, Resident Doctors 


\section{Introduction}

Globalization has led to easy mobility of people and goods around the world which has paved the way for efficient disease transmission, resulting in the frequent occurrence of outbreaks of infectious diseases. Among the emerging diseases, Zika Virus (ZIKV) disease has recently become a major VBD of international concern in low and middleincome countries. Zika Virus Disease (ZVD) is a mosquitoborne arbovirus infection caused by the Zika virus, a Flavivirus from the family Flaviviridae. ${ }^{1}$ It is spread mostly by the bite of an infected Aedes species mosquito (Ae. aegypti and Ae. albopictus) which bite mostly during the day but also at night. ${ }^{2}$ It was first identified in Uganda in 1947 in monkeys and later identified in humans in 1952 in Uganda and The United Republic of Tanzania. Subsequently, outbreaks of Zika virus disease have been recorded in Africa, the Americas, Asia and the Pacific. ${ }^{3}$

Recently, the transmission of Zika virus has also been reported from mother to fetus during pregnancy, through sexual contact, transfusion of blood and blood products, and organ transplantation. Although symptoms of ZVD among infected are mild, there is an increased risk of neurologic complications associated with Zika virus infection in adults and children, including Guillain-Barré syndrome, neuropathy, and myelitis. ${ }^{3}$ Also, infection during pregnancy can cause infants to be born with microcephaly and other congenital malformations, known as congenital Zika syndrome. Infection with Zika virus is also associated with other complications of pregnancy including preterm birth and miscarriage. ${ }^{4}$

In India, the first four proven cases of the ZIKV were reported in 2017. This was followed by major outbreaks in the states of Rajasthan and Madhya Pradesh in 2018. ${ }^{5}$ These outbreaks in India highlighted the spread of this disease beyond geographical barriers owing to the growing globalization, increased travel and ubiquitous presence of its vector, the Aedes mosquito.

Zika virus disease is an emerging infectious disease of international concern with a potential to cause outbreaks in developing countries especially India owing to its favorable climate for the Zika virus as well as adequate densities of vector mosquito for disease transmission. Frontline healthcare workers, including the Resident doctors need to be aware and vigilant of such potential outbreaks in the future in order to contain them at the earliest. Hence, this study was conducted to assess the knowledge and awareness of the Resident doctors toward managing ZVD in a tertiary care hospital in Goa.

\section{Methods}

The present hospital-based cross-sectional study was conducted among Resident doctors of Goa Medical College and Hospital. A total of 188 Resident doctors from various departments were interviewed using a self-administered, semi-structured questionnaire to obtain details regarding personal characteristics and their knowledge regarding the Zika virus disease. The study was conducted over a period of four months (March-June 2019). IEC approval was obtained prior to the commencement of the study. Informed written consent was taken from each participant prior to the interview.

The sampling method used was purposive sampling. All the Resident doctors of various Departments who were available in their respective workplace at the time of visit by our investigators were included in the study. Strict confidentiality of their responses was assured prior to their interview. Resident doctors who did not give consent and those who were not available at the time of the visit were excluded from the study.

Data was entered and analyzed using SPSS software version 22.

\section{Result}

Of the 188 Resident doctors, 80 (42.6\%) were males and $108(57.4 \%)$ were females. Based on the year of residency, it was observed that $65(34.6 \%)$ of the Resident doctors were in their first year of residency while only 17 (9\%) were Senior Residents (Figure 1). Most of the Resident doctors i.e. 184 (98\%) were aware of the Zika virus disease. Of all the Resident doctors, 140 (74.5\%) said that they were aware of ZVD cases occurring in India. A good number of the Resident doctors i.e. 112 (59.6\%) knew the genetic composition of the Zika virus. A high number i.e. 139 (73.9\%) of the Resident doctors were aware of the mosquito vector that transmits Zika disease. Whereas only 76 (40.4\%) Resident doctors were aware of the correct breeding sites of these mosquito vectors (Table 1 ).

When inquired regarding the mode of transmission of Zika virus, a majority of the Resident doctors i.e. 176 (93.6\%) of them said that it is transmitted through a mosquito bite. More than half of the Resident doctors i.e. 106 (56.4\%) were aware of the transplacental route of transmission of the Zika virus. Only 66 (35.1\%) of the Resident doctors said that the Zika virus is also transmitted via sexual route and through blood transfusions. Whereas only 24 (12.8\%) of the Resident doctors knew correctly all the modes of transmission of Zika virus disease.

When asked about the signs and symptoms of Zika virus disease, only 29 (15.4\%) of the Resident doctors could correctly state the approximate proportion of asymptomatic cases among those who are infected with Zika virus disease. Only $23(12.4 \%)$ of the Resident doctors were aware of the common symptoms and signs seen in cases of Zika virus disease. In contrast, as much as 133 (70.7\%) of the 
Resident doctors were correctly aware of the trimester with the highest risk of Zika virus transmission from mother to child. Also, a high number of Resident doctors i.e. 154 (81.9\%) were aware of the most common adverse outcome of maternal Zika virus infection.

When inquired about the knowledge regarding the diagnosis of Zika virus infection, a small number i.e. 27 (14.3\%) of the Resident doctors were aware of the fetal findings indicative of maternal zika virus infection. Only 110 (58.5\%) of the Resident doctors were aware of the correct methods of diagnosis Zika virus infection. Whereas, an even smaller number of Resident doctors i.e. 79 (42\%) knew about the isolation of the Zika virus.

A high number i.e. 183 (97.3\%) Resident doctors correctly said that Zika virus disease can be prevented and majority i.e. 180 (95.7\%) of the Resident doctors were aware of the preventive measures for the Zika virus infection. On inquiry about their source of information regarding zika virus disease, majority i.e. 120 (63.8\%) obtained their information from the internet followed by 88 (46.8\%) of the Resident who stated that their source of information was news from television and newspaper. About one third i.e. 62 (32.9\%) of the Resident doctors mentioned that they read about Zika virus disease from journal articles.

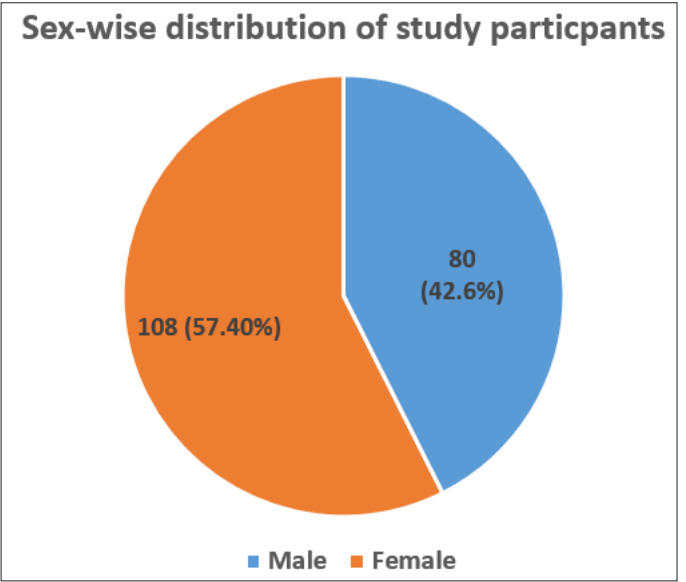

Figure I.Sex-wise distribution study participants Distribution of study participants based on year of Residency

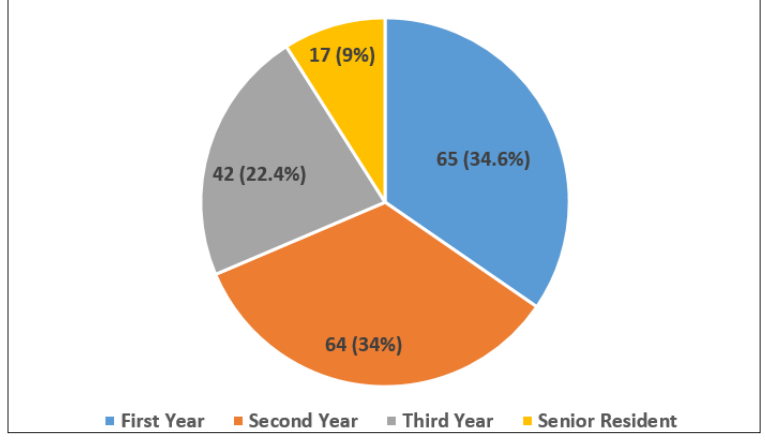

Figure 2.Distribution of study participants based on year of Residency
Table I.Awareness of Resident doctors regarding Zika virus disease

\begin{tabular}{|c|c|c|c|}
\hline \multicolumn{4}{|c|}{ Knowledge regarding Zika virus disease } \\
\hline $\begin{array}{l}\text { Sr. } \\
\text { No. }\end{array}$ & Knowledge & Frequency & $\begin{array}{c}\text { Percentage } \\
(\%)\end{array}$ \\
\hline & $\begin{array}{c}\text { Aware about Zika virus } \\
\text { disease }\end{array}$ & 184 & 98.0 \\
\hline & $\begin{array}{l}\text { Zika virus disease in } \\
\text { India }\end{array}$ & 140 & 44.5 \\
\hline & $\begin{array}{c}\text { Genetic composition } \\
\text { of Zika virus }\end{array}$ & 112 & 59.6 \\
\hline & Mosquito vector & 139 & 73.9 \\
\hline & $\begin{array}{l}\text { Preferred breeding site } \\
\text { for mosquito vector }\end{array}$ & 76 & 40.4 \\
\hline \multicolumn{4}{|c|}{ Knowledge regarding mode of transmission } \\
\hline 1. & Mosquito bite & 176 & 93.6 \\
\hline 2. & Sexual transmission & 66 & 35.1 \\
\hline 3. & Blood transfusion & 66 & 35.1 \\
\hline 4. & Air-borne & 16 & 8.5 \\
\hline \multirow[t]{2}{*}{5.} & Food and water & 13 & 6.9 \\
\hline & Transplacental & 106 & 56.4 \\
\hline
\end{tabular}

Only 24 (12.8\%) of the Resident doctors were aware of all the modes of transmission of Zika virus.

\begin{tabular}{|c|c|c|c|}
\hline \multicolumn{3}{|c|}{ Knowledge regarding symptoms of Zika virus disease } \\
\hline 1. & $\begin{array}{c}\text { Proportion of } \\
\text { asymptomatic cases } \\
\text { among infected }\end{array}$ & 29 & 15.4 \\
\hline 2. & $\begin{array}{c}\text { Common signs and } \\
\text { symptoms }\end{array}$ & 23 & 12.2 \\
\hline 3. & $\begin{array}{c}\text { Trimester with highest } \\
\text { risk of mother to child } \\
\text { transmission }\end{array}$ & 133 & 70.7 \\
\hline 4. & $\begin{array}{c}\text { Most common adverse } \\
\text { outcome of maternal } \\
\text { Zika virus infection }\end{array}$ & 154 & 81.9 \\
\hline Knowledge regarding diagnosis of Zika virus disease \\
\hline 1. & $\begin{array}{c}\text { Fetal findings leading } \\
\text { to ZVD suspicion }\end{array}$ & 27 & 14.3 \\
\hline 2. & $\begin{array}{c}\text { Method of diagnosis } \\
\text { of ZVD }\end{array}$ & 110 & 58.5 \\
\hline 3. & Isolation of Zika virus & 79 & 42 \\
\hline Knowledge regarding prevention of Zika virus disease
\end{tabular}




\section{Discussion}

Most of the Resident doctors i.e. 184 (98\%) were aware of the Zika virus disease while 140 (74.5\%) said that they were aware of ZVD cases occurring in India. Though a high number of Resident doctors were aware of Zika virus disease, a significant number of the Resident doctors were unaware of such cases occurring in India. Thus, the most important step against ZVD is to reinforce the knowledge of healthcare providers to efficiently detect and respond quickly to such outbreaks. Since the Resident doctors are the frontline workers who come in contact with patients in hospitals, they should be trained in not only detecting cases of ZVD but also should be capable of managing patients affected by it. A good number of the Resident doctors i.e. 112 (59.6\%) knew the genetic composition of the Zika virus. Zika virus belongs to the Flaviviridae family, thus it is related to dengue, yellow fever, Japanese encephalitis, and West Nile viruses. ${ }^{6}$ It is necessary to know the basic virology of the Zika virus to understand the pathogenesis of ZVD and distinguish ZVD from other viral infections presenting like ZVD.

A high number i.e. 139 (73.9\%) of the Resident doctors were aware of the mosquito vector that transmits Zika disease. Whereas only 76 (40.4\%) Resident doctors were aware of the correct breeding sites of these mosquito vectors. A similar study done by Gupta $\mathrm{N}$ et al in Chandigarh reported that $66.3 \%$ of the study participants were aware of the mosquito vector responsible for ZVD transmission. ${ }^{7}$ When inquired regarding the mode of transmission of Zika virus, a majority of the Resident doctors i.e. 176 (93.6\%) reported that it is transmitted through mosquito bite. Whereas only 24 $(12.8 \%)$ of them were aware of all the modes of transmission of Zika virus. In a similar study done among public secondary school teachers in the Philippines by Gregorio ER, Jr. et al, $80.3 \%$ of the study participants mentioned that Zika virus disease is transmitted through a mosquito bite. This was followed by mother to child transmission (22.8\%) and through blood transfusion (17.1\%). ${ }^{8}$

Only 29 (15.4\%) of the Resident doctors could correctly state the approximate proportion of asymptomatic cases among those who are infected with the Zika virus disease. The clinical presentation of ZVD in humans is often mild or asymptomatic and due to the recent increase in the number of symptomatic or suspected cases of ZVD across continents, it is necessary that all the healthcare providers are aware of the occurrence of such cases in order to prevent misdiagnosis of Zika virus disease among those infected especially pregnant women due to its predisposition to poor fetal outcomes following maternal Zika virus infection. ${ }^{9}$ It is noteworthy that only $23(12.4 \%)$ of the Resident doctors were aware of the common symptoms and signs seen in cases of Zika virus disease. A study done among junior
Resident doctors in a tertiary care hospital in New Delhi by Sulania A et al reported that only 7 (5.6\%) of 125 knew about all the signs and symptoms of ZVD. ${ }^{10}$ As much as 133 $(70.7 \%)$ of the Resident doctors were correctly aware of the trimester with the highest risk of Zika virus transmission from mother to child and small number i.e. 27 (14.3\%) of the Resident doctors were aware of the fetal findings leading to the suspicion of maternal zika virus infection. As much as $154(81.9 \%)$ were aware of the most common adverse outcomes of maternal Zika virus infection. Despite mild clinical symptoms in the mother, ZIKV infection during pregnancy is deleterious to the fetus and is associated with fetal death, fetal growth restriction, and a spectrum of central nervous system abnormalities. ${ }^{11}$ Thus it is necessary that Resident doctors especially those in the fields of obstetrics, neonatology and radiology be aware of the common presentations of Zika virus disease to avoid missing or delaying the diagnosis of potential cases of ZVD.

Only 110 (58.5\%) of the Resident doctors were aware of the correct methods of diagnosis Zika virus infection. Whereas even smaller number of Resident doctors i.e. 79 (42\%) knew about the isolation of the Zika virus. In a similar study done among private dental practitioners by Gupta N in Chandigarh, it was seen that only $7 \%$ of them knew the diagnostic test available for ZVD. ${ }^{7}$ As per the directives given by the MoHFW, Government of India, Zika virus should be diagnosed through PCR (polymerase chain reaction) and virus isolation from blood samples. It also states that diagnosis by serology is not recommended. ${ }^{12}$

Majority i.e. 183 (97.3\%) Resident doctors correctly stated that Zika virus disease can be prevented and 180 (95.7\%) of the Resident doctors were aware of some preventive measures for the Zika virus infection. A study done by Sulania $A$ et al among junior Residents in a tertiary care hospital in New Delhi reported that $24.8 \%$ of the junior Residents knew about all the ways to prevent infection whereas $46 \%$ of them knew about some of the ways to prevent infection from Zika virus. ${ }^{10}$ On inquiry about their source of information regarding the zika virus disease, majority i.e. 120 (63.8\%) obtained their information from the internet followed by $88(46.8 \%)$ of the Resident who stated that their source of information was news from television and newspaper. In a study done by A Sulania et al, it was reported that $79.4 \%$ of the junior Residents used internet and social media to gain knowledge regarding ZVD followed by $43.8 \%$ of the junior Residents who gained information through discussions with seniors and colleagues. ${ }^{10}$

\section{Conclusion}

In conclusion, the overall knowledge of Resident doctors in Goa regarding the Zika virus disease is low especially regarding the modes of transmission, signs and symptoms and diagnosis of the Zika infection. This is a matter of 
concern as Resident doctors are mostly the first point of contact for the patients seeking healthcare in tertiary care hospitals. Thus, it is necessary that basic knowledge and training regarding the Zika virus disease should be included in the current medical curriculum. Also, there should be regular CMEs and workshops on ZVD for the training of the Resident doctors and trainee medical doctors. Further emergency response training should be available to individuals interested in gaining additional knowledge and skills to assist in response to an outbreak of Zika virus disease.

\section{Conflicts of Interest: None}

\section{References}

1. Musso D, Gubler DJ. Zika Virus. Clinical Microbiology Reviews 2016; 29(3): 487-524.

2. Centers for Disease Control and Prevention. What We Know About Zika. Atlanta, USA; CDC. 2014 [cited 2019 Dec 21]. Available from: https://www.cdc.gov/zika/ about/index.html.

3. World Health Organization. Zika virus [Factsheet]. Geneva, Switzerland: WHO; 2018. [cited 2019 Dec 21]. Available from: https://www.who.int/news-room/ fact-sheets/detail/zika-virus.

4. Chibueze EC, Tirado V, Lopes K da S, Balogun OO, et al. Zika virus infection in pregnancy: A systematic review of disease course and complications. Reprod Health. 2017 Feb 28 [cited 2019 Dec 21]; 14. Available from: https:// www.ncbi.nlm.nih.gov/pmc/articles/PMC5330035/.

5. World Health Organization. Zika virus infection: India. Geneva, Switzerland: WHO; 2018. [cited 2019 Dec 21]. Available from: http://www.who.int/emergencies/ diseases/zika/india-november-2018/en/.

6. Hayes EB. Zika Virus Outside Africa. Emerg Infect Dis 2009; 15(9): 1347-1350.

7. Gupta N, Randhawa RK, Thakar S, Bansal M et al Knowledge regarding Zika virus infection among dental practitioners of tricity area (Chandigarh, Panchkula and Mohali), India. Niger Postgrad Med J 2016; 23(1): 33-37.

8. Jr ERG, Medina JRC, Lomboy MFTC, Talaga ADP et al. Knowledge, attitudes, and practices of public secondary school teachers on Zika Virus Disease: A basis for the development of evidence-based Zika educational materials for schools in the Philippines. PLOS ONE 2019; 14(3): e0214515.

9. World Health Organization. Zika situation report: Zika and potential complications [Internet]. Geneva, Switzerland: WHO; 2016 [cited 2020 Jan 26]. Available from: https://apps.who.int/iris/bitstream/ handle/10665/204371/zikasitrep_12Feb2016_ eng.pdf; jessionid=7A06D778F579DD6907C43D19110E337B?sequence=1.

10. Sulania A, Khokhar A. Knowledge and attitude regarding
Zika virus disease among junior Residents of a tertiary care hospital in Delhi, India. J Mahatma Gandhi Inst Med Sci [serial online] 2019 [cited 2019 Dec 21];24:3943. Available from: http://www.jmgims.co.in/text. asp?2019/24/1/39/254130.

11. Brasil P, Pereira JP, Moreira ME, Ribeiro Nogueira RM, et al. Zika Virus Infection in Pregnant Women in Rio de Janeiro. New England Journal of Medicine 2016; 375(24): 2321-2334.

12. Ministry of Health and Family Welfare, Government of India. Guidelines on Zika Virus Disease [Internet]. 2016. Available from: https://ncdc.gov.in/WriteReadData/ 1892s/File566.pdf. 